\title{
Mutual interactions of the apicomplexan parasites Toxoplasma gondii and Eimeria tenella with cultured poultry macrophages

Runhui Zhang ${ }^{1 *}$, Ahmed Thabet ${ }^{1,2}$, Lysanne Hiob ${ }^{1,4}$, Wanpeng Zheng ${ }^{1}$, Arwid Daugschies ${ }^{1,4}$ and Berit Bangoura ${ }^{1,3}$

\begin{abstract}
Background: Toxoplasma gondii and Eimeria tenella are two common parasites in poultry. Mixed infections are likely to occur frequently in chickens due to the high prevalence of both pathogens. In this study, we investigate the co-occurrence of the two pathogens in the same immunocompetent host cell population towards potential parasite-parasite as well as altered patterns of parasite-host interactions.
\end{abstract}

Methods: Primary macrophages from chicken blood were co-infected in vitro with T. gondii tachyzoites (RH strain) and E. tenella sporozoites (Houghton strain) for $72 \mathrm{~h}$. Morphological observations by light microscopy and assessments of parasite replication by quantitative real-time PCR (qPCR) were performed at 24, 48 and $72 \mathrm{~h}$ post-infection (hpi). Six host cell immune factors previously linked to $T$. gondii or E. tenella infection were selected for gene expression analysis in this study.

Results: Distinct morphological changes of macrophages were observed during mixed infection at $24 \mathrm{hpi}$ and immunological activation of host cells was obvious. Macrophage mRNA expression for iNOS at 48 hpi and for TNF-a at $72 \mathrm{hpi}$ were significantly elevated after mixed infection. Distinct upregulation of IL-10 was also present during coinfection compared to Eimeria mono-infection at 48 and $72 \mathrm{hpi}$. At $72 \mathrm{hpi}$, the total number of macrophages as well as the number of both parasites decreased markedly. As measured by qPCR, E. tenella population tended to increase during T. gondii co-infection, while T. gondii replication was not distinctly altered.

Conclusions: Mutual interactions of T. gondii and E. tenella were observed in the selected co-infection model. The interactions are supposed to be indirect considering the observed changes in host cell metabolism. This study would thus help understanding the course of co-infection in chickens that may be relevant in terms of veterinary and zoonotic considerations.

Keywords: Toxoplasma gondii, Eimeria tenella, Co-infection, in vitro, Chicken macrophage

\section{Background}

Toxoplasma gondii and Eimeria tenella are two coccidian parasites in poultry. Toxoplasma gondii is a heteroxenous parasite and may inhabit a wide range of vertebrate species as intermediate host, which may harbor the cyst stages in various tissues [1] following tachyzoite replication. Several reports showed high seroprevalence of $T$. gondii in chickens worldwide [2-4]. In contrast, E. tenella

\footnotetext{
* Correspondence: zhangrunhui423@gmail.com

${ }^{1}$ Institute of Parasitology, Centre for Infectious Diseases, Leipzig University,

Leipzig, Germany

Full list of author information is available at the end of the article
}

is very host-specific and monoxenous, infecting particularly the caecal mucosa of chicken $[5,6]$.

Mixed infections are likely to occur in chickens, particularly under free-ranging conditions. Many studies investigate host-pathogen interactions of single $T$. gondii or Eimeria spp. infections [7-9], but little is known to date about the pathogen-pathogen-host cell interactions for simultaneous co-infections with species of these two parasite genera. Tachyzoites of $T$. gondii and merozoites of Eimeria differ in many features; however, asexual stages of these parasites share ultrastructural similarities $[10,11]$. It was shown that transgenic E. tenella (Et-TgSAG1) may induce certain immunoprotection against T. gondii [12]. On the

(C) The Author(s). 2018 Open Access This article is distributed under the terms of the Creative Commons Attribution 4.0 International License (http://creativecommons.org/licenses/by/4.0/), which permits unrestricted use, distribution, and 
other hand, $T$. gondii as a vaccine vector has a partially protective effect against coccidiosis [13]. Mixed infections with $T$. gondii and Eimeria spp. were found in wild rabbits in a recent case report [14]. The ability of $T$. gondii to suppress the macrophage-associated defense to Mycobacterium avium has been shown in vitro [15].

Chicken macrophages are crucially involved in the host immune response to both $T$. gondii and E. tenella $[2,16,17]$. In coccidiosis, chicken macrophages are also involved in sporozoite transport during the endogenous phase of Eimeria development [18]. Thus, it appears likely that simultaneous appearance of these two apicomplexan parasites may affect the reaction of host macrophages to parasite infection. Experimental in vivo studies revealed a partial mutual interaction between $T$. gondii and E. tenella [19] in chickens.

Immune response of primary monocyte-derived macrophages is stimulated in vitro by $T$. gondii tachyzoites [20] and E. tenella sporozoites [21]. High expression of pro-inflammatory Th1 cytokines is typically related to macrophage function in T. gondii infection [22]. Previous investigations also showed that Th1/Th2 pro-inflammatory cytokines related to macrophages are involved in the host response to Eimeria infection [23-25]. High production of Th2 inflammatory mediators such as interleukin 6 (IL-6) was reported in T. gondii and E. tenella mono-infections $[26,27]$. In vitro replication of $T$. gondii is enhanced significantly when murine macrophages are pre-treated with IL-6 prior to infection [28]. In vitro infection of avian macrophages by $E$. tenella sporozoites upregulates nitric oxide (NO) production and inducible nitric oxide synthase (iNOS) transcription $[29,30]$. Induced NO production by macrophages is generally related to cytokines such as IFN- $\gamma$ and tumor necrosis factor $\alpha$ (TNF- $\alpha$ ) which play a vital role in immunity of chicken against coccidiosis and toxoplasmosis [31, 32]. Various effects of in vivo co-infection of T. gondii and E. tenella in chickens [19] were observed on IFN- $\gamma$, TNF- $\alpha$, IL-10 and IL-12.

In this study, we aimed to understand the simultaneous co-occurrence of the two pathogens in the same avian immune-competent host cell population and the interaction with the innate immunity against each single pathogen. Additionally, pathogen-pathogen interactions in terms of invasion and replication potential were investigated. The ability of macrophages to host both parasites simultaneously is also demonstrated.

\section{Methods}

\section{Macrophages and parasites}

Macrophages were separated and collected from chicken peripheral blood mononuclear cells (PBMC) according to established protocols [33]. The isolated PBMC $(5 \times$ $10^{6}$ cells per well) were suspended in RPMI-1640 medium (Sigma, Taufkirchen, Germany) supplemented with $5 \%$ chicken serum and $5 \%$ fetal bovine serum, penicillin (100 U/ml, PAA), streptomycin $(0.1 \mathrm{mg} / \mathrm{ml}, \mathrm{PAA})$, and amphotericin B $(0.0025 \mathrm{mg} / \mathrm{ml}$, PAA), seeded into 24-well plates and incubated at $41{ }^{\circ} \mathrm{C}$ with $5 \% \mathrm{CO}_{2}$. They were grown to about $90 \%$ confluence within $96 \mathrm{~h}$ cultivation time. Free transgenic $T$. gondii RH-GFP tachyzoites (type I strain, kindly provided by Professor Dominique Soldati-Favre, University of Geneva Medical School, Switzerland) were harvested from infected human foreskin fibroblast (HFF) cultures by mechanical destruction. Eimeria. tenella Houghton strain (kindly provided by Professor Damer Blake, Royal Veterinary College, UK) and transgenic Houghton-YFP strain (kindly provided by Professor Xun Suo, China Agricultural University, China) sporozoites were gained by oocyst excystation following an established protocol [34]. Briefly, the oocyst wall of E. tenella was destroyed mechanically with $0.5 \mathrm{~mm}$ glass beads (BioSpec Products, Bartlesville, OK, USA). Excystation of sporozoites was performed by incubation with $0.25 \%$ trypsin $(\mathrm{w} / \mathrm{v})$ (Carl Roth, Karlsruhe, Germany) and 4\% sodium taurocholic acid (w/v) (Sigma-Aldrich, Taufkirchen, Germany) at $41{ }^{\circ} \mathrm{C}$ for $90 \mathrm{~min}$. Purified sporozoites were collected by passage through columns of nylon wool and DE-52 resin (Whatman, GE Healthcare, USA) with 1\% glucose phosphate-buffered saline (PBS) at $\mathrm{pH} 7.6$ (follow buffer). E. tenella Houghton strain sporozoites were used for all experiments except for laser scanning analyses where E. tenella Houghton-YFP strain was utilized.

\section{Mono- and co-infections}

Infection doses for both parasites were optimized prior to the co-infection trial (data not shown). Six groups were set-up for in vitro infection studies in primary macrophages: TH, T. gondii infection with $5 \times 10^{5}$ tachyzoites (high-dose); TL, T. gondii infection with $2.5 \times 10^{5}$ tachyzoites (low-dose); EH, E. tenella infection with $5 \times$ $10^{5}$ sporozoites (high-dose); EL, E. tenella infection with $2.5 \times 10^{5}$ sporozoites (low-dose); CI (co-infection), mixed infection with $T$. gondii $2.5 \times 10^{5}$ tachyzoites and E. tenella $2.5 \times 10^{5}$ sporozoites; NC, uninfected negative control cell cultures. At $96 \mathrm{~h}$ after isolation of PBMCs, purified primary macrophages were infected with parasites according to their group and incubated at $41{ }^{\circ} \mathrm{C}$. At 12 hours post-infection (hpi), the wells were rinsed once with PBS to remove extracellular sporozoites. The medium was changed and cell cultures were further incubated at $41{ }^{\circ} \mathrm{C}$. The course of infection was monitored until 72 hpi.

\section{Positive control MDBK culture infection}

In addition to the primary macrophages, Madin-Darby Bovine Kidney (MDBK) cell line cultures were used. In those cell cultures, six infection groups were formed 
(TH, TL, EH, EL, CI and NC) as described before. They were carried along in parallel to macrophage trials as controls for parasite replication analysis without macrophage-specific influence on parasite-parasite interaction. MDBK cultures were maintained and infected at $41{ }^{\circ} \mathrm{C}$ to enable comparison to primary chicken macrophage cultures under comparable incubation conditions. MDBK host cell cultures were tested before to be easily maintained and multiplied at this temperature (data not shown).

\section{Assessments of parasite replication}

Parasite replication was assessed by two parameters: microscopic examination over time and parasite-specific real-time quantitative PCR (qPCR). Morphological differences and parasite population densities were visualized in all groups at 2, 24, 48 and 72 hpi by light microscopy. For qPCR, samples from each group were collected at 24, 48 and 72 hpi. DNA extraction was carried out using the QIAamp DNA Mini Kit' (Qiagen, Hilden, Germany) according to the manufacturer's protocol for cell cultures. The T. gondii-specific 529-bp repeat element was used to detect replication in a probe-based qPCR [35]. Standard curve samples were generated by gradient 10-fold dilutions of $10^{7}$ tachyzoites to obtain absolute DNA copy numbers for $T$. gondii amplification. Replication of $E$. tenella was measured by ITS1 fragment quantification in a SYBR Green-based PCR as described before [36]. pSCA-17 plasmid standard dilutions were prepared as measure for the relative copy number of $E$. tenella DNA as described by Thabet et. al. [37]. The qPCRs were carried out in a Stratagene MX3000P cycler (Stratagene, La Jolla, USA). The cycling program for $T$. gondii detection included $95{ }^{\circ} \mathrm{C}$ for $15 \mathrm{~min}$ (initial denaturation), followed by 40 cycles of $95{ }^{\circ} \mathrm{C}$ for $15 \mathrm{~s}$ (denaturation), $60{ }^{\circ} \mathrm{C}$ for $1 \mathrm{~min}$ (annealing), and $72{ }^{\circ} \mathrm{C}$ for $15 \mathrm{~s}$ (extension). The cycling program for E. tenella was performed as follows: $95{ }^{\circ} \mathrm{C}$ for 5 min (initial denaturation), followed by 40 cycles of $95{ }^{\circ} \mathrm{C}$ for $30 \mathrm{~s}$ (denaturation), $62{ }^{\circ} \mathrm{C}$ for $20 \mathrm{~s}$ (annealing), and $72{ }^{\circ} \mathrm{C}$ for $20 \mathrm{~s}$ (extension). For E. tenella, a subsequent melting curve analysis $\left(95^{\circ} \mathrm{C}\right.$ for $1 \mathrm{~min}, 62^{\circ} \mathrm{C}$ for $30 \mathrm{~s}$ and $95^{\circ} \mathrm{C}$ for 30 s) was applied to create the dissociation curve and ensure amplicon consistency. Data represent the mean of three replicates with an acceptable standard deviation for $\mathrm{Ct}$ values of less than 0.5 .

\section{Immune fluorescence assay (IFA) and confocal laser scanning microscopy (CLSM)}

In addition to light microscopy, CLSM (TCS-SP8, Leica, Bensheim, Germany) was applied to observe the morphology of the infected cell cultures, for localization of parasites within the host cells, and to estimate the extent of intracellular replication. Therefore, $2 \times 10^{6}$ PBMC per well were cultivated in 8-well chamber slides (Ibidi, Martinsried, Germany) for 4 days to grow pure cultures of primary macrophages. Infection conditions were the same as mentioned above for all infection groups $(\mathrm{TH}$, TL, EH, EL, CI and NC). For CLSM, cultures were fixed with methanol for $10 \mathrm{~min}$ before further processing. 4', 6-diamidino-2-phenylindole (DAPI, Sigma-Aldrich, USA) was used to stain cell nuclei. Cell imaging was carried out by Leica Application Suite X (LAS X, Leica Microsystems, Wetzlar, Germany).

\section{Cytokine analysis}

Samples were collected at 24, 48 and $72 \mathrm{hpi}$, and stored at $-80{ }^{\circ} \mathrm{C}$. Six cell culture replicates per infection group were analyzed for each time point. RNA was extracted using the RNeasy ${ }^{\circ}$ Mini Kit (Qiagen, Hilden, Germany) following the manufacturer's instructions. Total RNA was measured using a NanoPhotometer NP80 (Implen, Munich, Germany). The complementary DNA (cDNA) was synthesized using the Revert-Aid ${ }^{\circ}$ first strand cDNA synthesis kit (Thermo Fisher Scientific, Darmstadt, Germany), according to the manufacturer's instructions. Briefly, $10 \mathrm{ng} / \mu \mathrm{l}$ total RNA were combined with $4 \mu \mathrm{l} 5 \times$ reaction buffer, $1 \mu \mathrm{l}$ RiboLock RNase Inhibitor $(20 \mathrm{U} / \mu \mathrm{l})$, $2 \mu \mathrm{l}$ 10mM dNTP Mix, $1 \mu \mathrm{l}$ RevertAid M-MuLV RT $(200 \mathrm{U} / \mu \mathrm{l}), 1 \mu \mathrm{l}$ of Oligo dT Primer $(100 \mu \mathrm{M})$ and RNase-free water to a total volume of $20 \mu$ l. The mixture was incubated at $42{ }^{\circ} \mathrm{C}$ for $60 \mathrm{~min}$ and the reaction was terminated by heating at $70{ }^{\circ} \mathrm{C}$ for $5 \mathrm{~min}$.

The mRNA expression levels of chicken host cell cytokines were measured by reverse transcription quantitative PCR (RT-qPCR). Specific sequences of the primers for TNF- $\alpha$, IL-6, IL-10, IL-12, IFN- $\gamma$ and iNOS cDNA amplification were selected (Table 1). Data normalization was performed based on the two chicken cell housekeeping genes glyceraldehyde 3-phosphate dehydrogenase (GAPDH) and glucose-6-phosphate dehydrogenase $(\mathrm{G} 6 \mathrm{PDH})$ as described before [38]. For qPCR assay, 10 $\mu \mathrm{l}$ SYBR Green master mix (Thermo Fisher Scientific, Germany), $6.6 \mu \mathrm{l}$ water, $0.4 \mu \mathrm{l}$ ROX solution, $2 \mu \mathrm{l}$ cDNA template, $0.5 \mu \mathrm{l}$ forward primer and $0.5 \mu \mathrm{l}$ reverse primer were used per reaction. The cycling program included $95{ }^{\circ} \mathrm{C}$ for $10 \mathrm{~min}$ (initial denaturation), followed by 40 cycles of $95{ }^{\circ} \mathrm{C}$ for $30 \mathrm{~s}$ (denaturation), $60{ }^{\circ} \mathrm{C}$ for $30 \mathrm{~s}$ (annealing), and $72{ }^{\circ} \mathrm{C}$ for $1 \mathrm{~min}$ (extension). A subsequent melting curve program $\left(95{ }^{\circ} \mathrm{C}\right.$ for $1 \mathrm{~min}, 55^{\circ} \mathrm{C}$ for $30 \mathrm{~s}$ and $95^{\circ} \mathrm{C}$ for $30 \mathrm{~s}$ ) was applied to create the dissociation curve for each PCR run.

\section{Statistics}

Relative parasite DNA copy numbers as derived from qPCR results were calculated and presented as mean value $(n=3)$ for each time point after infection. Cytokines were quantified from RT-qPCR results using qBase 
Table 1 Sequence of the primers used for chicken cytokine analysis by RT-qPCR

\begin{tabular}{|c|c|c|c|c|}
\hline \multirow{2}{*}{$\begin{array}{l}\text { RNA } \\
\text { target }\end{array}$} & \multirow{2}{*}{$\begin{array}{l}\text { Accession } \\
\text { No. }\end{array}$} & \multicolumn{2}{|l|}{ Primer sequences $\left(5^{\prime}-3^{\prime}\right)$} & \multirow[t]{2}{*}{ Reference } \\
\hline & & Forward & Reverse & \\
\hline GAPDH & K01458 & GGTGGTGCTAAGCGTGTTAT & АССTCTGTCATCTCTCTCCACA & {$[38]$} \\
\hline G6PDH & Al981686 & CGGGAACCAAATGCACTTCGT & CGCTGCCGTAGAGGTATGGGA & {$[64]$} \\
\hline $\mathrm{IFN}-\gamma$ & Y07922 & AGCTGACGGTGGACCTATTATT & GGCTITGCGCTGGATTC & [38] \\
\hline IL-6 & AJ309540 & CAAGGTGACGGAGGAGGAC & TGGCGAGGAGGGATTTCT & [38] \\
\hline $\mid \mathrm{L}-10$ & AJ621614 & CGGGAGCTGAGGGTGAA & GTGAAGAAGCGGTGACAGC & [38] \\
\hline $\mid \mathrm{LL}-12$ & NM_213571 & AGACTCCAATGGGCAAATGA & CTCTTCGGCAAATGGACAGT & [38] \\
\hline TNF-a & AY765397.1 & CTTCTGAGGCATTTGGAAGC & ACTGGGCGGTCATAGAACAG & {$[65]$} \\
\hline iNOS & U46504 & TGGGTGGAAGCCGAAATA & GTACCAGCCGTTGAAAGGAC & [38] \\
\hline
\end{tabular}
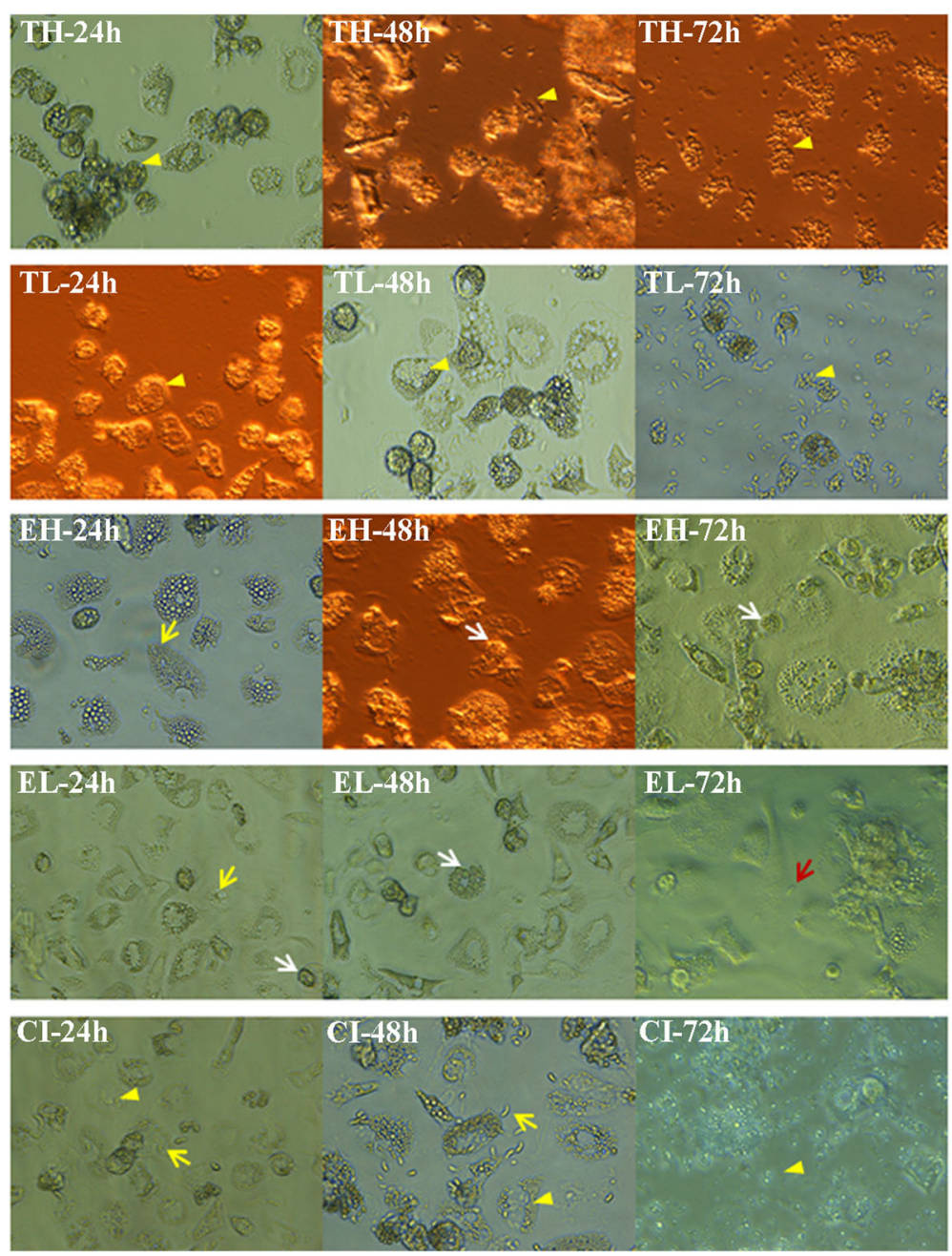

Fig. 1 Morphological visualization of primary macrophage cell cultures at 24, 48, 72 hpi by light microscopy. Yellow arrowhead: T. gondii tachyzoites; yellow arrow, E. tenella sporozoites; white arrow, E. tenella meronts; red arrow: E. tenella merozoites. Abbreviations: TH, high-dose infection with $T$. gondii; $T L$, low-dose infection with $T$. gondii; $E H$, high-dose infection with E. tenella; $E$ L, low-dose infection with $E$. tenella; $\mathrm{Cl}$, co-infected group. Negative control group (NC) not shown 
Plus 2.3 (Biogazelle NV, Belgium). Reference target stability and cytokine X-fold change differences between the infection groups were analyzed. X-fold change of cytokine expression was also calculated in comparison to the $\mathrm{NC}$ group data for each respective time point. Non-parametric Kolmogorov-Smirnov test was performed to test for normal distribution of data. Thereafter, the cytokine data were analysed statistically by ANOVA followed by Student's t-test (SPSS version $20^{\circ}$, IBM, New York, USA). Data are presented as mean \pm standard error of the mean (SEM). A $P$-value $<0.05$ is considered as statistically significant.

\section{Results}

\section{Visual observation by light microscopy and CLSM}

All infection groups were examined by light microscopy at four time points after infection (Fig. 1 and Table 2). At $2 \mathrm{hpi}$, invasion and adherence of E. tenella sporozoites were more obvious than for $T$. gondii tachyzoites in mono- and co-infected cell cultures (data not shown). Macrophage vacuolization occurred $24 \mathrm{hpi}$ in the $\mathrm{CI}$ and Toxoplasma groups (TL and TH), but to a lesser extent in the Eimeria groups (EL and EH). Meanwhile, most of the E. tenella sporozoites remained in the intracellular sporozoite stage with low numbers of meronts appearing in both Eimeria-infected groups (EL and EH) and the CI group. At 48 hpi, many macrophages were detached in the infected cultures of $\mathrm{TH}$ group and $\mathrm{CI}$ group. There was a large number of free tachyzoites in the TH group with microscopic findings similar to $72 \mathrm{hpi}$ in TL group and CI group. However, less free tachyzoites were visualized in TL and CI groups at $48 \mathrm{hpi}$. After $72 \mathrm{~h}$, low numbers of $E$. tenella second generation of merozoites were found in the mono-infection groups EL and EH occasionally. By light microscopy, lowest numbers of macrophages were counted at $48 \mathrm{hpi}$. Almost no intact-appearing macrophage could be observed in T. gondii infection groups and co-infected group CI at $72 \mathrm{hpi}$.

In CLSM experiments using fluorescing transgenic parasites, it was observed that in co-infected macrophage cultures $T$. gondii partially replicated within host cells that also harbored E. tenella (Fig. 2a) from 24 hpi onwards. At $48 \mathrm{hpi}, T$. gondii meront numbers dominated over $E$. tenella meront numbers in the co-infected cell cultures of group CI (Fig. 2b). Host cell aggregation was seen in parallel with replication of $T$. gondii from $24 \mathrm{hpi}$.

\section{Assessment of parasite replication by qPCR}

DNA copy quantities representing T. gondii tachyzoites and E. tenella (all stages) in all samples were measured by qPCR. The average parasite replication dynamics were different in mono-infected groups compared to the CI group for both parasites (Fig. 3). In mono-infected groups, qPCR results indicated that $T$. gondii was able to replicate considerably in infected chicken macrophages of groups $\mathrm{TH}$ and TL over the study period. In the TH group, a final decrease in $T$. gondii stage numbers was seen $72 \mathrm{~h}$.

\section{Positive control MDBK cultures}

Both parasites could be demonstrated in infected MDBK monolayers. Generally, in co-infected MDBK cell populations, T. gondii parasite numbers were slightly higher in comparison to mono-infected cultures as assessed by qPCR. However, no significant difference between

Table 2 Light microscopy findings by infection group and time point compared to uninfected NC group

\begin{tabular}{|c|c|c|c|c|c|c|c|c|c|c|c|c|}
\hline & \multicolumn{3}{|l|}{$2 \mathrm{hpi}$} & \multicolumn{3}{|c|}{$24 \mathrm{hpi}$} & \multicolumn{3}{|c|}{$48 \mathrm{hpi}$} & \multicolumn{3}{|c|}{72 hpi } \\
\hline & $\mathrm{EH}$ & EL & $\mathrm{Cl}$ & $\mathrm{EH}$ & EL & $\mathrm{Cl}$ & $\mathrm{EH}$ & EL & $\mathrm{Cl}$ & $\mathrm{EH}$ & EL & $\mathrm{Cl}$ \\
\hline Attached macrophages & +++ & +++ & +++ & +++ & +++ & ++ & +++ & +++ & ++ & ++ & ++ & + \\
\hline Macrophage vacuolization & - & - & + & ++ & + & ++ & + & + & +++ & ++ & ++ & +++ \\
\hline Free $\mathrm{Et}^{\mathrm{a}}$ sporozoites & + & + & + & - & - & - & - & - & - & - & - & - \\
\hline Intracellular $\mathrm{Et}^{\mathrm{a}}$ sporozoites & + & + & + & + & + & + & - & - & - & - & - & - \\
\hline Intracellular meronts & - & - & - & + & + & ++ & ++ & ++ & ++ & ++ & ++ & ++ \\
\hline \multirow[t]{2}{*}{$\mathrm{Et}^{\mathrm{a}}$ merozoites } & - & - & - & - & - & - & - & - & - & + & + & $-c$ \\
\hline & TH & TL & $\mathrm{Cl}$ & TH & TL & $\mathrm{Cl}$ & TH & TL & $\mathrm{Cl}$ & TH & TL & $\mathrm{Cl}$ \\
\hline Attached macrophages & +++ & +++ & +++ & ++ & +++ & ++ & + & ++ & ++ & - & + & + \\
\hline Macrophage vacuolization & ++ & + & + & ++ & + & ++ & +++ & ++ & +++ & - & +++ & +++ \\
\hline Free $\mathrm{Tg}^{\mathrm{b}}$ tachyzoites & +++ & ++ & ++ & + & - & - & +++ & + & + & + & +++ & +++ \\
\hline Intracellular $\mathrm{Tg}^{\mathrm{b}}$ tachyzoites & + & + & + & ++ & + & + & + & ++ & ++ & + & ++ & +++ \\
\hline
\end{tabular}

Findings were scored semiquantitatively (-, not observed; +, low amounts; ++, moderate amounts; +++, high amounts). Infection groups: TH, high-dose infection with T. gondii; TL, low-dose infection with T. gondii; $\mathrm{EH}$, high-dose infection with E. tenella; EL, low-dose infection with E. tenella, Cl co-infected group.

${ }^{\mathrm{a}} \mathrm{Et}$, E. tenella

${ }^{\mathrm{b}} \mathrm{Tg}, T$. gondii

${ }^{c}$ Not clearly observable due to the numerous replication of $T$. gondii tachyzoites presented in cell culture by light microscopy 


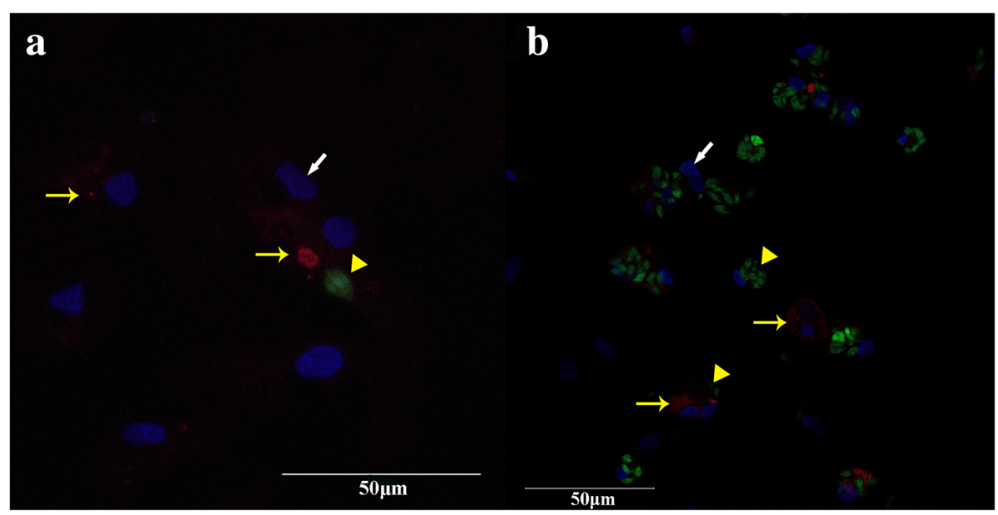

Fig. 2 Morphological visualization during co-infection of primary macrophage cell cultures by confocal laser scanning microscopy (CLSM). In co-infected macrophages, populations of $T$. gondii partially replicated in host cells which also stained positive for E. tenella. Nuclei of macrophages are stained blue (DAPI), T. gondii RH-GFP appear green and E. tenella Houghton-YFP red. a Cell culture co-infected with T. gondii and E. tenella at 24 hpi. b Cell culture co-infected with $T$. gondii and E. tenella at 48 hpi. White arrow: macrophage nuclei; yellow arrowhead: T. gondii tachyzoites; yellow arrow: E. tenella sporozoites or meronts

mono- and co-infection was observed for the replication of both parasites (data not shown).

Compared to macrophages, the stage numbers of both parasites at 72 hpi were significantly different in MDBK cells (Fig. 4). Toxoplasma gondii tachyzoites were not able to replicate sustainably in the MDBK co-infected culture and were not demonstrable after $24 \mathrm{hpi}$. The number of $T$. gondii tachyzoites was significantly lower in all mono- and co-infected MDBK cultures compared to the population in similarly infected macrophage cell cultures throughout the infection period. Conversely, replication of $E$. tenella was approximately quadrupled in relation to the infection dose at 24 hpi in co-infected MDBK cultures. By light microscopic observation, infected MDBK host cells showed less morphological alterations than macrophages. Eimeria tenella merozoites were clearly observed at $72 \mathrm{hpi}$.

\section{Cytokine analysis}

The relative mRNA expression of six cytokines was measured until 72 hpi by qPCR (Fig. 5) and compared with the uninfected group $\mathrm{NC}$ as $\mathrm{X}$-fold changes. From the investigated cytokine panel, only IL-6 did not show relevant alterations in any group at any time point.

The measurement at 24 hpi showed a distinct elevation for iNOS and IFN- $\gamma$ mRNA expression in EH and EL as well as CI groups $\left(F_{(5,31)}=4.81, P<0.05\right.$ compared to NC group). In contrast, TNF- $\alpha$ was only slightly increased. For groups $\mathrm{TH}$ and $\mathrm{TL}$, iNOS and IFN- $\gamma$ were not significantly altered though TNF- $\alpha$ and IL-10 were slightly increased. Only in group EL, an observable increase in IL-12 expression was induced $\left(F_{(4,26)}=3.76, P<0.05\right.$ compared to all other groups). No statistically significant differences were revealed between mono-infected groups

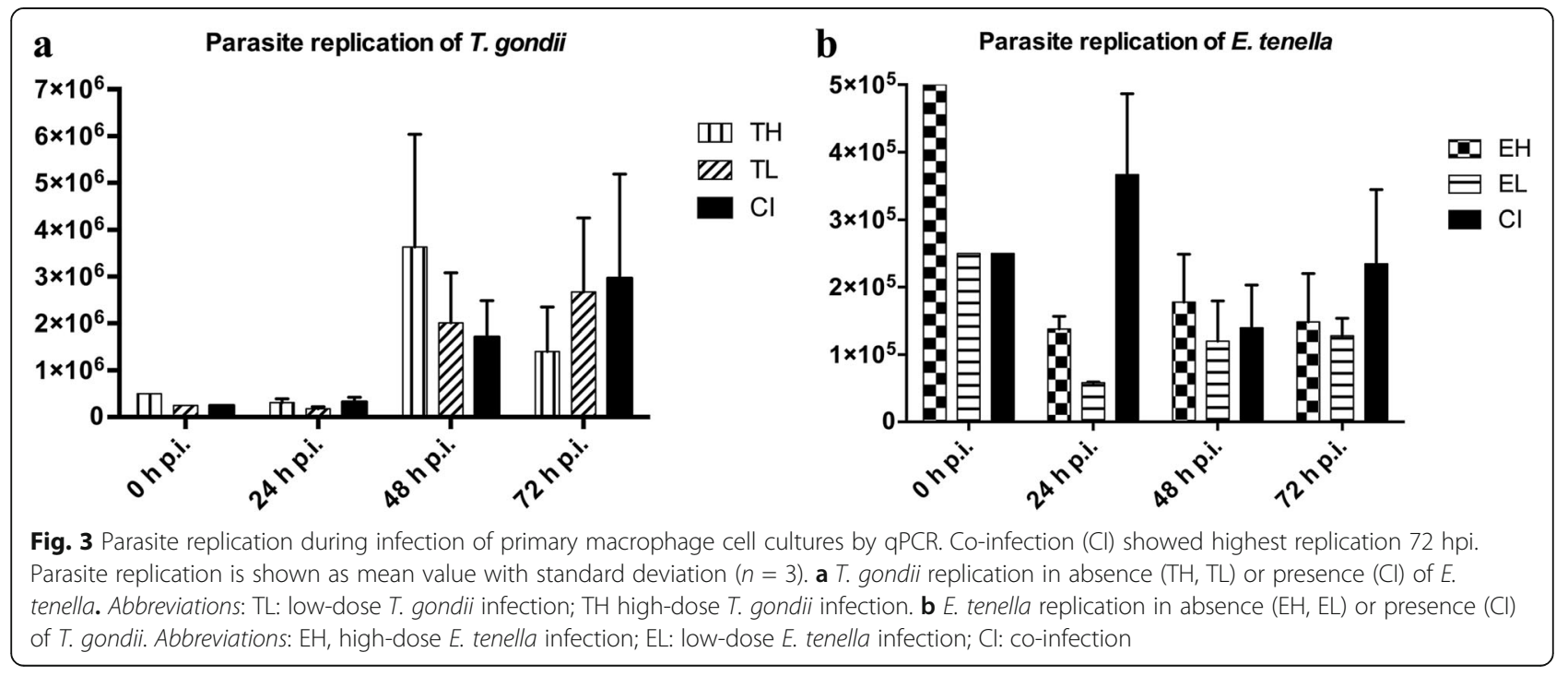




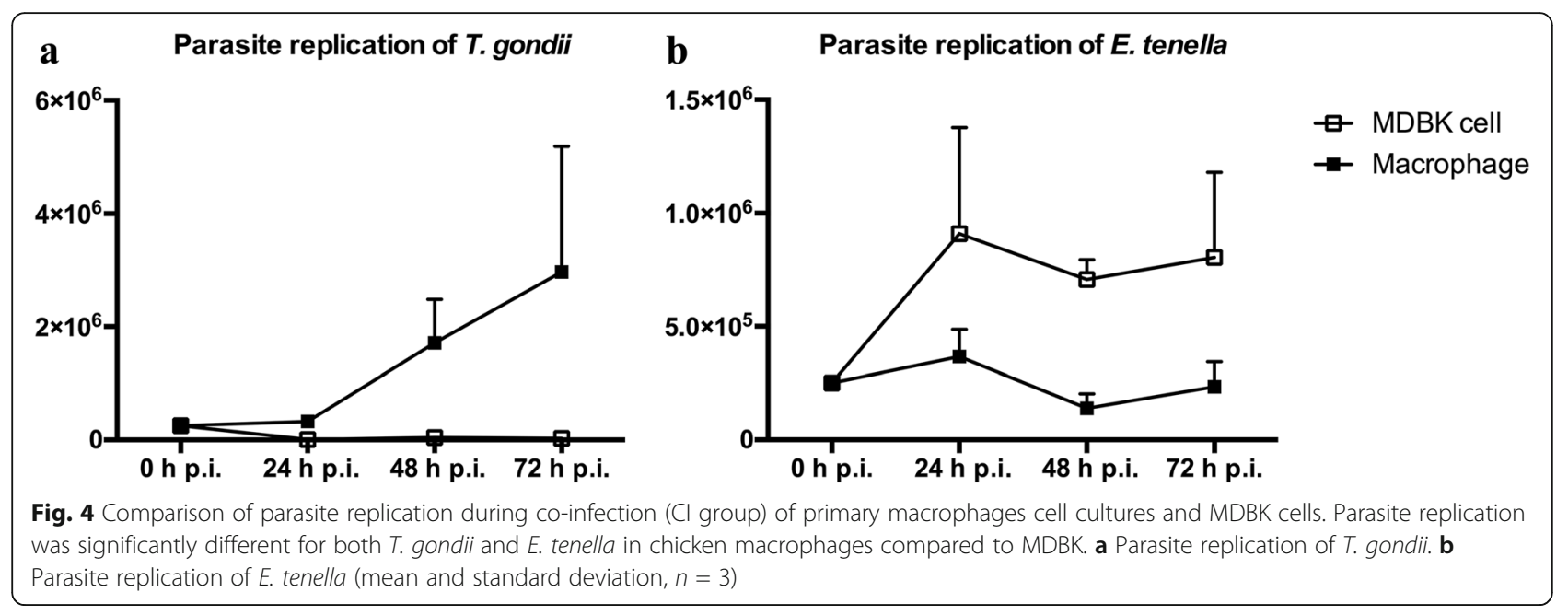

and the CI group for IFN- $\gamma$, IL-10, IL-12 or TNF- $\alpha$, respectively.

At 48 hpi, IFN- $\gamma$ mRNA expression was highest in group CI though group differences were not statistically significant. Significantly increased levels of IL-10 were observed in groups $\mathrm{TH}\left(F_{(4,26)}=4.20, P=0.020\right.$ compared to TL) and CI $\left(F_{(4,26)}=4.20, P=0.025\right.$ compared to $\mathrm{EL} ; F_{(4,26)}=4.20, P=0.105$ compared to TH). IL-12 was highly expressed in groups $\mathrm{EH}, \mathrm{EL}$, and $\mathrm{TH}$. In contrast, IL-12 mRNA expression was not elevated in group CI $\left(F_{(4,23)}=2.31, P=0.026 ; F_{(4,23)}=2.31, P=0.029\right.$ compared to EL and TH). Expression of iNOS mRNA peaked in group $\mathrm{CI}$ at $48 \mathrm{hpi}\left(F_{(4,26)}=2.32, P=0.006\right.$ compared to EL). TNF- $\alpha$ was not altered significantly by any infection mode until $48 \mathrm{hpi}\left(F_{(4,24)}=0.656, P>0.05\right.$ for all group comparisons).

At $72 \mathrm{hpi}$, IFN- $\gamma$ mRNA expression levels were significantly increased for group $\operatorname{EL}\left(F_{(4,24)}=1.64, P=0.021\right.$ compared to $\mathrm{EH})$. IL-10 expression was higher in groups $\mathrm{TH}$ and $\mathrm{CI}\left(F_{(4,24)}=1.20, P<0.05\right.$ compared to $\mathrm{EH}$ and EL). IL-12 expression was upregulated in all infected groups except for TL to a 2-fold to 3-fold extent. A moderate upregulation of iNOS as well as TNF- $\alpha$ expression were seen in all $T$. gondii-infected groups TH, TL and CI.

\section{Discussion}

Investigations into physiological alterations associated with experimental infections with mixed Eimeria spp. in chickens were previously published $[39,40]$. However, to the best of our knowledge, there is only one published study of Eimeria spp. co-infection with T. gondii [19], probably because of the widely assumed sub-clinical character of toxoplasmosis in chickens [4]. The lack in primary clinical presentation does not necessarily imply that $T$. gondii infections may not influence the course of other infectious diseases in chickens. Since both pathogens, Eimeria spp. and T. gondii, are widely distributed in chicken flocks $[4,6,41]$, this study focused on their potential interactions on the avian innate immune cells using primary macrophages as a model. Although the single published in vivo co-infection study of $T$. gondii and E. tenella did not demonstrate major mutual interaction in terms of inflammation and pathological findings, a significantly lower E. tenella oocyst excretion was observed in the co-infection group compared to Eimeria mono-infection group [19]. In the present in vitro T. gondii and E. tenella co-infection study, we found that there were various mutual effects between those parasites in chicken primary macrophages.

It was previously shown that chicken macrophages isolated from peritoneal exudates are capable of $E$. tenella sporozoite phagocytosis at 2-3 hpi [42]. There are convincing evidences that the clinical course and lethality of $E$. tenella infection were reduced by activated macrophages $[43,44]$. On the other hand, sporozoites of Eimeria utilize chicken macrophages as transport cells [18], and tachyzoites of T. gondii can multiply in chicken primary macrophages $[33,45]$. In the present study, we established a PBMC-derived macrophage culture for successful replication of both E. tenella and T. gondii. In general, $T$. gondii seemed to be better adapted to replication within chicken macrophages; however, E. tenella stages multiplied as well. As expected, both low-dose mono-infected groups EL and TL showed a slower and more sustainable increase in parasite numbers over time than the high-dose infected groups $\mathrm{EH}$ and $\mathrm{TH}$. In a primary cell culture with a limited availability of host cells, it seems plausible that a high infection dose destroys host cells faster; thus rapidly hampering parasites replication than a low initial number of parasites. Although E. tenella showed an initial decrease in total gene copy numbers, this was followed by a distinct increase in co-infected cultures only. This may reflect that $T$. gondii 

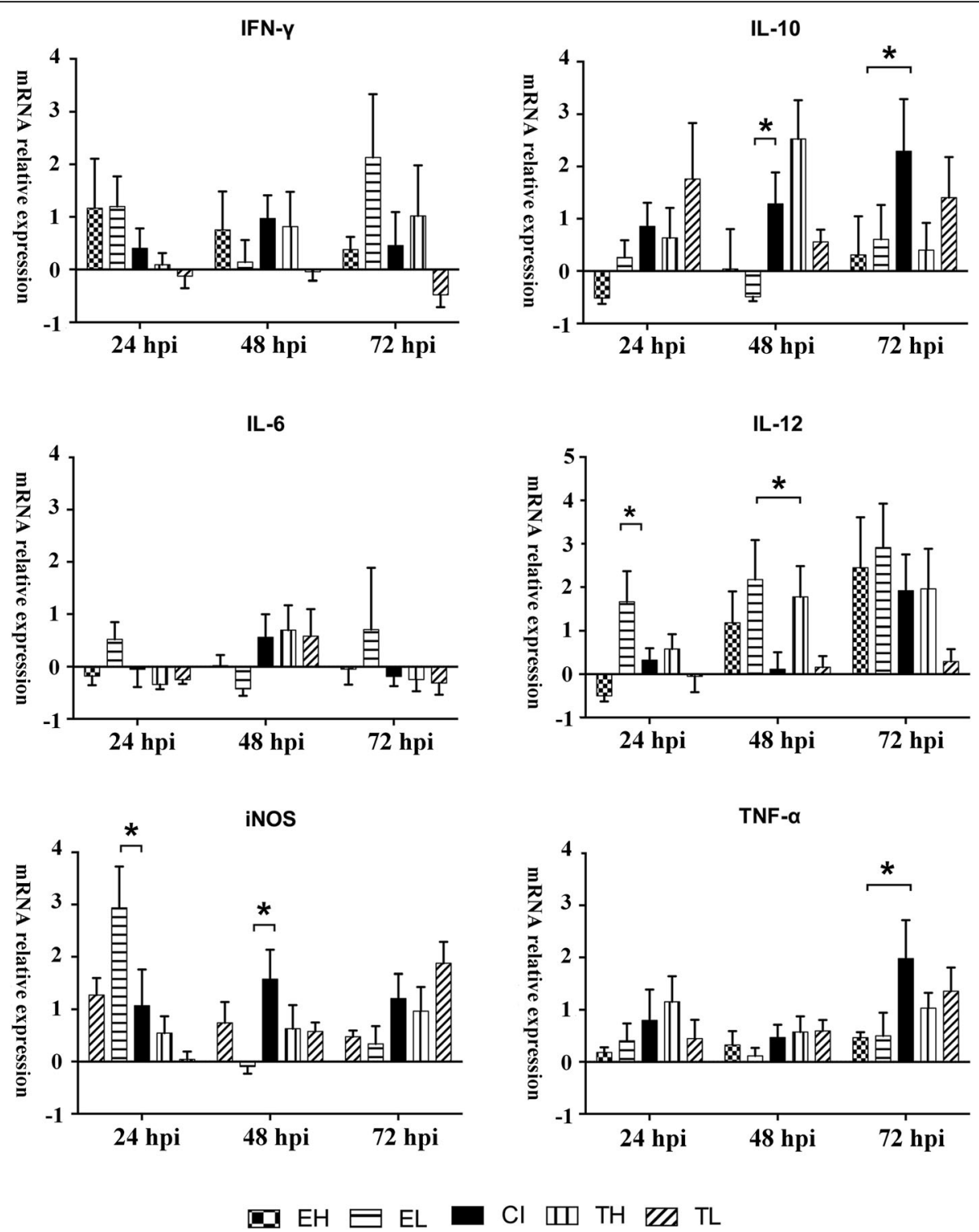

Fig 5 Macrophage mRNA relative cytokine expression by infection group. Normalization of data was performed on housekeeping genes GAPDH and G6PDH. The mRNA transcriptional levels of TNF-a, IL-6, IL-10, IL-12, IFN- $\gamma$, iNOS were determined by RT-qPCR. Displayed $x$-fold change values were calculated based on negative control $(\mathrm{NC})$ group replicates $(n=6)$. Statistical comparison was performed between the $\mathrm{Cl}$ group and other groups ( $\left.{ }^{P} P<0.05\right)$. Abbreviations: TH, high-dose infection with T. gondii; TL, low-dose infection with T. gondii; EH, high-dose infection with $E$. tenella; EL, low-dose infection with E. tenella; Cl, co-infected group

supports E. tenella replication in macrophages; however, this hypothesis needs further investigation.

Mixed Eimeria spp. infections in vivo did not exert mutual effects on replication of three poultry Eimeria species [46]. In contrast, in our in vitro model we found that $E$. tenella and $T$. gondii displayed interactions that were most pronounced towards the end of the study (72 hpi). At this time, both $T$. gondii and E. tenella were replicating more strongly in co-infected cultures than in the mono-infected controls. This effect was particularly pronounced for $E$. tenella. However, the capability of E. tenella to invade macrophages was not influenced by co-infection with $T$. gondii. Light microscopic observations showed that first generation meronts were the dominating stages of $E$. tenella in all mono- and co-infected cultures. Unfortunately, the chosen co-infection model is not able to investigate a potential influence of $T$. gondii on sexual $E$. tenella development. It can be speculated that the increase in asexual E. tenella seen during co-infection might only be temporary and stage-related since another recent in 
vivo investigation in our laboratory showed that a significantly low number of $E$. tenella oocysts were excreted by chicken co-infected with $T$. gondii than following Eimeria mono-infections [19]. In accord with our current findings, Hiob et al. [19] stated that the number of meronts in the intestine was not significantly altered by co-infection so the inhibiting effect of $T$. gondii on chicken Eimeria might be rather linked to the sexual development, which is not described to take place in macrophages.

The MDBK cell line was used to investigate growth and functions of $T$. gondii and E. tenella in vitro in various ways $[47,48]$. Regardless of mono- or co-infection, we found that reproduction of $T$. gondii tachyzoites was broadly lower in MDBK cells than in chicken primary macrophages. In contrast to $E$. tenella, $T$. gondii replicated much more strongly in the macrophage culture. It appears possible that the cell metabolism of MDBK cells is altered at $41{ }^{\circ} \mathrm{C}$, which is distinctly above the physiological bovine body temperature. However, no significant effect on parasite multiplication was found in co-infected MDBK cell cultures compared to primary chicken macrophages. This indicates an important role of the host cell type in induction or modulation of pathogen-pathogen interactions whereas the incubation temperature of $41{ }^{\circ} \mathrm{C}$ does not appear to play a major role in our model.

Chicken macrophages serve as phagocytes and regulatory immune cells. They produce cytokines, induce cytokine production in other immune cells, and destroy protozoans directly as part of the innate immune response $[49,50]$. Although chickens are considered to be important natural hosts for T. gondii [4] and the only host species for E. tenella [51], immunoregulatory mechanisms by avian primary macrophages during simultaneous $T$. gondii and E. tenella infections are not sufficiently elucidated. We could demonstrate that, besides affecting the parasite replication potential, primary macrophage cell cultures reacted in different ways to both parasites during monoand co-infections.

Macrophages are not the main source of IFN- $\gamma$ but they are capable of IFN- $\gamma$ expression [52]. IFN- $\gamma$ plays an important role in the replication inhibition of the two investigated parasites [53, 54]. Five other cytokines produced by macrophages were included in our investigation: Th2-supporting IL-6, Th1-supporting IL-12, IFN- $\gamma$-inhibiting IL-10, and innate immune response-related iNOS and TNF- $\alpha$. This panel was chosen because earlier studies clearly indicated the importance of those cytokines in coccidial infections [31, 46]. Single infections with $E$. tenella evoked host immune response which led to significant expression of cytokines such as IL-10 and IFN- $\gamma$ in the ceca [46]. In vivo, it was demonstrated that mRNA expression of IFN- $\gamma$, IL-12 and IL-10 was distinctly upregulated in the ceca of chickens at the early stage of co-infection with $T$. gondii and Eimeria spp.
[19]. In addition, high expression of those cytokines was observed in chickens co-infected with E. tenella and Clostridium perfringens [55]. Based on our observations in the co-infection model, using 12 hour intervals for cytokine expression measurements might be useful in the future to more comprehensively judge parasite-host cell interactions. However, we could observe several host cell reactions in this co-infected model.

In the present study, IFN- $\gamma$ mRNA levels were upregulated mainly due to $E$. tenella infection, whereas co-infection seemed to suppress this Th1-related cytokine. Similar findings were recorded for IL-12 mRNA expression. Thus, it can be assumed that the adaptive Th1 response is rather suppressed than triggered in co-infected macrophages compared to mono-infections. In a recent study [56], a significant upregulation at $2 \mathrm{hpi}$ and slight downregulation of IL-12 at 24 hpi were observed in a chicken macrophage cell line infected with $E$. tenella merozoites, which was diminishing over time. In contrast, IL-12 was upregulated by the end of the observation period in group $\mathrm{CI}$, which might be related to the development of $E$. tenella meronts. Interestingly, in contrast to the cited in vivo studies $[19,55]$, we did not observe a distinct increase in IL-12 mRNA expression in co-infected macrophages. Therefore, we assume that not macrophages but other immune cell populations are responsible for the previously observed in vivo increase of IL-12 expression. In chickens, IL-6 mRNA expression was not significantly affected. This indicates that Th2 stimulation by macrophage-derived IL-6 does not play a major role in this infection mode.

IL-10 mRNA upregulation was observed mainly in T. gondii infection with a delayed peak in group CI that coincides with increased $E$. tenella replication. Since one of the multiple functions of IL-10 is the downregulation of IFN- $\gamma$ expression, this corresponds clearly with the reduced transcription seen in CI. However, high expression of IL-10 in infected chickens is not associated to parasite multiplication or expression of cytokines like IFN- $\gamma$ and IL-12 during T. gondii RH-infection [57]. Thus, it seems as if in vivo multiple immune cell populations influence the Th1 response to apicomplexan parasites, with macrophages being an important part of the complex innate immune response.

In spite of the relatively low IFN- $\gamma$ levels in co-infected macrophages, reactive oxygen and nitrogen intermediates such as iNOS were produced in excess in these cells. This is interesting because IFN- $\gamma$ is generally assumed to trigger the macrophages to produce these metabolites [31, 58]. It was previously $[59,60]$ demonstrated that $T$. gondii is altering $\mathrm{NO}$ production inhibition in chicken monocyte-derived macrophages and macrophage cell lines. In the present study, iNOS seemed to play a vital role in macrophage response 
during co-infection (Fig. 5). Conversely, it was reported that iNOS was distinctly expressed during E. tenella infection in vivo or ex vivo [29]. This is in line with the general but moderate upregulation of iNOS mRNA expression in all infected groups seen in the present study.

Furthermore, we observed increased TNF- $\alpha$ expression in all infected groups, and this was particularly distinct in $T$. gondii-infected groups reaching a maximum at $72 \mathrm{hpi}$ in the co-infected group. TNF- $\alpha$ increase was described before in E. tenella-infected chicken macrophages [32, 61]. Other authors $[62,63]$ stated a synergistic anti-T. gondii effect of TNF- $\alpha$ and IFN- $\gamma$. Our study demonstrated that co-infection significantly upregulated TNF- $\alpha$ while parasite replication increased more than in mono-infected cultures. We conclude that TNF- $\alpha$ production may either not be sufficient to counteract parasite replication in our model, especially in the presence of low IFN- $\gamma$ levels, as indicated by Chang et al. [63], or that TNF- $\alpha$ mRNA expression does not exactly reflect actual TNF- $\alpha$ levels.

\section{Conclusions}

We demonstrated in vitro interactions between $T$. gondii and E. tenella in macrophages and MDBK cells. The findings of this study revealed that over a study period of 72 hpi, the replication of both parasites increased during co-infections compared to mono-infected cultures. Increased expression of IL-10 and TNF-a in co-infected cells demonstrates that interaction of both parasites is tightly linked to the host cell types and their various responses to infection. However, the present study leads to further questions. Additional experiments are needed to fully clarify the signaling pathways that are, e.g. leading to replication differences between mono- and co-infected cells. The presented findings are currently based solely on in vitro experiments that were chosen because of the defined conditions that allow for a more precise initial data interpretation. Future in vivo studies taking into account the natural interactions between different immune cell populations are needed to confirm our findings and their biological relevance, as well as to enable a betterunderstanding of the mechanisms of host-parasite and parasite-parasite interactions during co-infections. Additionally, investigations into subsequent infections with both pathogens will be helpful to estimate the relevance of non-simultaneous infections with both parasites that might be most relevant in the field.

\section{Abbreviations}

iNOS: inducible nitric oxide synthase; IL: Interleukin; IFN-ү: Interferon gamma; TNF-a: Tumor necrosis factor-a; TH: High-dose infection with T. gondii;

TL: Low-dose infection with T. gondii; EH: High-dose infection with E. tenella; EL: Low-dose infection with E. tenella; Cl: Co-infected group; hpi: hours postinfection; NC: Negative control group; MDBK: Madin-Darby Bovine Kidney; PBMC: Peripheral blood mononuclear cells; PBS: Phosphate-buffered saline; IFA: Immune fluorescence assay; CLSM: Confocal laser scanning microscopy

\section{Acknowledgements}

We thank Johannes Kacza and all members of the Institute of Parasitology, University Leipzig, especially Tina Goroll and Irene Malkwitz, for technical assistance and support.

\section{Funding}

This study is supported by a research doctoral fellowship to RZ granted by Akademie für Tiergesundheit (AfT) and Karl-Enigk-Stiftung (KES), Germany. The authors acknowledge support from the German Research Foundation (DFG) and Leipzig University within the programme of Open Access Publishing.

\section{Availability of data and materials}

All data generated or analysed during this study are included in this published article.

\section{Authors' contributions}

RZ designed the study, wrote the manuscript and performed the experiments. AT participated in the collection of parasites and chicken blood. $\mathrm{LH}$ and WZ analyzed data and helped to draft the manuscript. AD and BB critically revised the study design, data interpretation and manuscript. All authors read and approved the final manuscript.

\section{Ethics approval}

The animal experiments related to the blood sampling were approved by the responsible authorities (Landesdirektion Sachsen, Germany, trial registration number $\mathrm{V} 13 / 10)$.

Consent for publication

Not applicable.

\section{Competing interests}

The authors declare that they have no competing interests.

\section{Publisher's Note}

Springer Nature remains neutral with regard to jurisdictional claims in published maps and institutional affiliations.

\section{Author details}

${ }^{1}$ Institute of Parasitology, Centre for Infectious Diseases, Leipzig University, Leipzig, Germany. ${ }^{2}$ TCVS diagnostic laboratory-Gaza, Gaza strip, Palestine. ${ }^{3}$ Department of Veterinary Sciences, University of Wyoming, Laramie, WY, USA. ${ }^{4}$ Albrecht-Daniel-Thaer-Institute, Leipzig, Germany.

Received: 3 May 2018 Accepted: 27 July 2018

Published online: 06 August 2018

\section{References}

1. Dubey JP, Beattie CP. Toxoplasmosis of Animals and Man. Boca Raton: CRC Press, Inc; 1988.

2. Unno A, Suzuki K, Xuan X, Nishikawa Y, Kitoh K, Takashima Y. Dissemination of extracellular and intracellular Toxoplasma gondii tachyzoites in the blood flow. Parasitol Int. 2008:57:515-8.

3. Dubey JP, Salant H, Sreekumar C, Dahl E, Vianna MCB, Shen SK, et al. High prevalence of Toxoplasma gondii in a commercial flock of chickens in Israel, and public health implications of free-range farming. Vet Parasitol. 2004;121:317-22.

4. Dubey JP. Toxoplasma gondii infections in chickens (Gallus domesticus): prevalence, clinical disease, diagnosis and public health significance. Zoonoses Public Health. 2010;57:60-73.

5. Anderson WI, Giambrone JJ, Fletcher OJ Jr, Eidson CS, Reid WM. Demonstration of Eimeria tenella in bursa of Fabricius of chickens. Avian Dis. 1976:4:752-5.

6. Dalloul RA, Lillehoj HS. Poultry coccidiosis: recent advancements in control measures and vaccine development. Expert Rev Vaccines. 2006;5:143-63.

7. Hotop A, Buschtons S, Bangoura B, Zoller B, Koethe M, Spekker-Bosker K, et al. Humoral immune responses in chickens and turkeys after infection with Toxoplasma gondii by using recombinant antigens. Parasitol Res. 2014; 113:1473-80.

8. Chapman HD. Milestones in avian coccidiosis research: a review. Poult Sci. 2014;93:501-11. 
9. Milanova A, Santos R, Lashev L, Koinarski V, Fink-Gremmels J. Influence of experimentally induced Eimeria tenella infection on gene expression of some host response factors in chickens. Bulg J Vet Med. 2016;19:47-56.

10. Soares Medeiros LC, Gomes F, Maciellr SSH, Docampo R, Moreno S, et al. Volutin granules of Eimeria parasites are acidic compartments and have physiological and structural characteristics similar to acidocalcisomes. J Eukaryot Microbiol. 2011;58:416-23.

11. Rose ME, Lee DL. Interactions in vitro between sporozoites of Eimeria tenella and host peritoneal exudate cells: electron microscopal observations. Z Parasitenk. 1977:54:1-7.

12. Tang X, Yin G, Qin M, Tao G, Suo J, Liu X, Suo X. Transgenic Eimeria tenella as a vaccine vehicle: expressing TgSAG1 elicits protective immunity against Toxoplasma gondii infections in chickens and mice. Sci Rep. 2016;6:29379.

13. Zou J, Huang $X-X$, Yin G-W, Ding Y, Liu X-Y, Wang H, et al. Evaluation of Toxoplasma gondii as a live vaccine vector in susceptible and resistant hosts. Parasit Vectors. 2011;4:168.

14. Mason S, Dubey JP, Smith JE, Boag B. Toxoplasma gondii coinfection with diseases and parasites in wild rabbits in Scotland. Parasitology. 2015;142:1415-21.

15. Black CM. Co-infection of macrophages modulates interferon gamma and tumor necrosis factor-induced activation against intracellular pathogens. J Exp Med. 1990;172:977-80.

16. Hériveau C, Dimier-Poisson I, Lowenthal J, Naciri M, Quéré P. Inhibition of Eimeria tenella replication after recombinant IFN- $\gamma$ activation in chicken macrophages, fibroblasts and epithelial cells. Vet Parasitol. 2000;92:37-49.

17. Quéré P, Pierre J, Hoang M-D, Esnault E, Domenech J, Sibille P, DimierPoisson I. Presence of dendritic cells in chicken spleen cell preparations and their functional interaction with the parasite Toxoplasma gondii. Vet Immunol Immunopathol. 2013;153:57-69.

18. Van Doorninck WM, Becker ER. Transport of sporozoites of Eimeria necatrix in macrophages. J Parasitol. 1957:43:40-4.

19. Hiob L, Koethe M, Schares G, Goroll T, Daugschies A, Bangoura B. Experimental Toxoplasma gondii and Eimeria tenella co-infection in chickens. Parasitol Res. 2017;116:3189-203.

20. Malkwitz I, Berndt A, Zhang R, Daugschies A, Bangoura B. Replication of Toxoplasma gondii in chicken erythrocytes and thrombocytes compared to macrophages. Parasitol Res. 2017;116:123-31.

21. Zhou Z, Wang Z, Cao L, Hu S, Zhang Z, Qin B, et al. Upregulation of chicken TLR4, TLR15 and MyD88 in heterophils and monocyte-derived macrophages stimulated with Eimeria tenella in vitro. Exp Parasitol. 2013;133:427-33.

22. Denkers EY, Kim L, Butcher BA. In the belly of the beast: Subversion of macrophage proinflammatory signaling cascades during Toxoplasma gondii infection. Cell Microbiol. 2003;5:75-83.

23. Hong $\mathrm{YH}$, Lillehoj HS, Lee SH, Dalloul RA, Lillehoj EP. Analysis of chicken cytokine and chemokine gene expression following Eimeria acervulina and Eimeria tenella infections. Vet Immunol Immunopathol. 2006;114:209-23.

24. Laurent F, Mancassola R, Lacroix S, Menezes R, Naciri M. Analysis of chicken mucosal immune response to Eimeria tenella and Eimeria maxima infection by quantitative reverse transcription-PCR. Infect and Immun. 2001;69:2527-34.

25. Ovington KS, Alleva LM, Kerr EA. Cytokines and immunological control of Eimeria spp. Int J Parasitol. 1995;25:1331-51.

26. Lyons RE, Anthony JP, Ferguson DJP, Byrne N, Alexander J, Roberts F, Roberts CW. Immunological studies of chronic ocular toxoplasmosis: up-regulation of major histocompatibility complex class I and transforming growth factor $\beta$ and a protective role for interleukin-6. Infect Immun. 2001;69:2589-95.

27. Lynagh GR, Bailey M, Kaiser P. Interleukin- 6 is produced during both murine and avian Eimeria infections. Vet Immunol Immunopathol. 2000;76:89-102.

28. Beaman $\mathrm{MH}$, Hunter CA, Remington JS. Enhancement of intracellular replication of Toxoplasma gondii by IL-6. Interactions with IFN-gamma and TNF-alpha. J Immunol. 1994;153:4583-7.

29. Lillehoj HS, Li G. Nitric oxide production by macrophages stimulated with coccidia sporozoites, lipopolysaccharide, or interferon- $\gamma$, and its dynamic changes in SC and TK strains of chickens infected with Eimeria tenella. Avian Dis. 2004:48:244-53.

30. Allen PC. Nitric oxide production during Eimeria tenella infections in chickens. Poultry Sci. 1997;76:810-3.

31. Lieberman LA, Hunter CA. The role of cytokines and their signaling pathways in the regulation of immunity to Toxoplasma gondii. Int Rev Immunol. 2009;21:373-403.

32. Zhang S, Lillehoj HS, Ruff MD. In vivo role of tumor necrosis-like factor in Eimeria tenella infection. Avian Dis. 1995;39:859-66.
33. Malkwitz I, Berndt A, Daugschies A, Bangoura B. Long-term investigations on Toxoplasma gondii-infected primary chicken macrophages. Parasitol Res. 2013;112:3115-22

34. Ekert J, Braun R, Shirley MW, Courdet P. Biotechnology Guidelines on Techniques in Coccidiosis Research. European Coorperation in the field of and Technical Research. COST. 1992;89:220-1.

35. Edvinsson B, Lappalainen M, Evengård B. Real-time PCR targeting a 529-bp repeat element for diagnosis of toxoplasmosis. Clin Microbiol Infect. 2006; 12:131-6.

36. Kawahara F, Taira K, Nagai S, Onaga H, Onuma M, Nunoya T. Detection of five avian Eimeria species by species-specific real-time polymerase chain reaction assay. Avian Dis. 2008:52:652-6.

37. Thabet A, Alnassan AA, Daugschies A, Bangoura B. Combination of cell culture and $\mathrm{qPCR}$ to assess the efficacy of different anticoccidials on Eimeria tenella sporozoites. Parasitol Res. 2015;114:2155-63.

38. Park SS, Lillehoj HS, Allen PC, Park DW, FitzCoy S, Bautista DA, Lillehoje EP. Immunopathology and cytokine responses in broiler chickens coinfected with Eimeria maxima and Clostridium perfringens with the use of an animal model of necrotic enteritis. Avian Dis. 2008:52:14-22.

39. Jenkins M, Allen P, Wilkins G, Klopp S, Miska K. Eimeria praecox infection ameliorates effects of Eimeria maxima infection in chickens. Vet Parasitol. 2008;155:10-4

40. Jenkins M, Fetterer R, Miska K. Co-infection of chickens with Eimeria praecox and Eimeria maxima does not prevent development of immunity to Eimeria maxima. Vet Parasitol. 2009;161:320-3.

41. Shirley MW, Smith AL, Tomley FM. The biology of avian Eimeria with an emphasis on their control by vaccination. Adv Parasitol. 2005;60:285-330.

42. Long PL, Rose ME. Growth of Eimeria tenella in vitro in macrophages from chicken peritoneal exudates. Z Parasitenk. 1976;48:291-4.

43. Lee E-H, Al-Izzi SA. Selective killing of macrophages in the peritoneal cavity by carrageenan and its effect on normal infection of Eimeria tenella in chickens. Avian Dis. 1981:25:503-12.

44. Lillehoj HS, Kang SY, Keller L, Sevoian M. Eimeria tenella and E. acervulina: lymphokines secreted by an avian $T$ cell lymphoma or by sporozoitestimulated immune T lymphocytes protect chickens against avian coccidiosis. Exp Parasitol. 1989:69:54-64.

45. Meirelles MN, de Souza W. Killing of Trypanosoma cruzi and Leishmania mexicana, and survival of Toxoplasma gondii, in chicken macrophages in vitro. J Submicrosc Cytol. 1985;17:327-34.

46. Cornelissen JBWJ, Swinkels WJC, Boersma WA, Rebel JMJ. Host response to simultaneous infections with Eimeria acervulina, maxima and tenella: a cumulation of single responses. Vet Parasitol. 2009;162:58-66.

47. Appleford PJ, Smith JE. Toxoplasma gondii: the growth characteristics of three virulent strains. Acta Trop. 1997;65:97-104.

48. Thabet A, Zhang R, Alnassan A-A, Daugschies A, Bangoura B. Anticoccidial efficacy testing: in vitro Eimeria tenella assays as replacement for animal experiments. Vet Parasitol. 2017:233:86-96.

49. Qureshi MA, Heggen CL, Hussain I. Avian macrophage: effector functions in health and disease. Dev Comp Immunol. 2000;24:103-19.

50. Dalloul RA, Bliss TW, Hong Y-H, Ben-Chouikha I, Park DW, Keeler CL, Lillehoj HS. Unique responses of the avian macrophage to different species of Eimeria. Mol Immunol. 2007;44:558-66.

51. Blake DP, Clark EL, Macdonald SE, Thenmozhi V, Kundu K, Garg R, et al. Population, genetic, and antigenic diversity of the apicomplexan Eimeria tenella and their relevance to vaccine development. Proc Natl Acad Sci USA. 2015;112:E5343-50.

52. Gessani S, Belardelli F. IFN- $\gamma$ expression in macrophages and its possible biological significance. Cytokine Growth Factor Rev. 1998;9:117-23.

53. Dimier-Poisson $I H$, Soundouss $Z$, Naciri M, Bout DT, Quéré P. Mechanisms of the Eimeria tenella growth inhibitory activity induced by concanavalin A and reticuloendotheliosis virus supernatants with interferon gamma activity in chicken macrophages and fibroblasts. Avian Dis. 1999:43:65-74.

54. Lillehoj HS, Choi KD. Recombinant chicken interferon-gamma-mediated inhibition of Eimeria tenella development in vitro and reduction of oocyst production and body weight loss following Eimeria acervulina challenge infection. Avian Dis. 1998:42:307-14.

55. Bangoura B, Alnassan AA, Lendner M, Shehata AA, Krüger M, Daugschies A. Efficacy of an anticoccidial live vaccine in prevention of necrotic enteritis in chickens. Exp Parasitol. 2014;145:125-34.

56. Chow Y-P, Wan K-L, Blake DP, Tomley F, Nathan S. Immunogenic Eimeria tenella glycosylphosphatidylinositol-anchored surface antigens (SAGs) 
induce inflammatory responses in avian macrophages. PLoS One. 2011;6: e25233.

57. Wille U, Villegas EN, Striepen B, Roos DS, Hunter CA. Interleukin-10 does not contribute to the pathogenesis of a virulent strain of Toxoplasma gondii. Parasite Immunol. 2001;23:291-6.

58. Adams $L B$, Hibbs JB, Taintor RR, Krahenbuhl JL. Microbiostatic effect of murine-activated macrophages for Toxoplasma gondii. Role for synthesis of inorganic nitrogen oxides from L-arginine. J Immunol. 1990;144:2725-9.

59. DaMatta RA, Seabra SH, Manhães L, de Souza W. Nitric oxide is not involved in the killing of Trypanosoma cruzi by chicken macrophages. Parasitol Res. 2000:86:239-43.

60. Guillermo L, DaMatta R. Nitric oxide inhibition after Toxoplasma gondi infection of chicken macrophage cell lines. Poult Sci. 2004;83:776-82.

61. Zhang S, Lillehoj HS, Ruff MD. Chicken Tumor Necrosis-Like Factor. 1. In vitro production by macrophages stimulated with Eimeria tenella or bacterial lipopolysaccharide. Poult Sci. 1995;74:1304-10.

62. de Titto EH, Catterall JR, Remington JS. Activity of recombinant tumor necrosis factor on Toxoplasma gondii and Trypanosoma cruzi. J Immunol. 1986;137:1342-5.

63. Chang HR, Grau GE, Pechere JC. Role of TNF and IL-1 in infections with Toxoplasma gondii. Immunology. 1990;69:33-7.

64. de Boever S, Vangestel C, de Backer P, Croubels S, Sys SU. Identification and validation of housekeeping genes as internal control for gene expression in an intravenous LPS inflammation model in chickens. Vet Immunol Immunopathol. 2008;122:312-7.

65. Nang NT, Lee JS, Song BM, Kang YM, Kim HS, Seo SH. Induction of inflammatory cytokines and toll-like receptors in chickens infected with avian H9N2 influenza virus. Vet Res. 2011:42:64.

Ready to submit your research? Choose BMC and benefit from:

- fast, convenient online submission

- thorough peer review by experienced researchers in your field

- rapid publication on acceptance

- support for research data, including large and complex data types

- gold Open Access which fosters wider collaboration and increased citations

- maximum visibility for your research: over $100 \mathrm{M}$ website views per year

At $\mathrm{BMC}$, research is always in progress.

Learn more biomedcentral.com/submissions 